\title{
EMPREENDEDORISMO \\ RURAL SUSTENTÁVEL \\ AGRICULTURA FAMILIAR DO SEMIÁRIDO: PROJETO DE EDUCAÇÃO AMBIENTAL VIDA DO SOLO, MUCAMBO, RIACHÃO \\ DO JACUÍPE BAHIA.
}

\author{
Adelson Ferreira \\ Soares $^{1}$ \\ Janúzia Souza \\ Mendes $^{2}$
}

\section{Resumo}

O presente trabalho destina-se a investigar como um projeto de educação ambiental criado por um agricultor familiar, em um sítio localizado no semiárido brasileiro, especificamente na comunidade de Mucambo, Riachão do Jacuípe, Bahia, é capaz de combinar técnicas de empreendedorismo em áreas rurais, desenvolvendo e usando ferramentas simples e inovadoras na gestão e no cultivo do solo, pecuária, produção de alimentos e armazenamento de água para consumo humano e animal, a ponto de se tornar uma referência nacional e internacional. O objetivo deste trabalho é, portanto, entender a importância do empreendedorismo, combinado com a educação ambiental para a mudança de vida dos agricultores familiares, diante da realidade cruel, que inclui a escassez de recursos naturais e financeiros na zona rural do semiárido baiano. Para atingir esse objetivo, foi adotado um estudo de caso e outras ferramentas de pesquisa, como pesquisa de campo, técnicas de observação e entrevista estruturada com abordagem qualitativa e análise de conteúdo que aponta o empreendedorismo, as técnicas inovadoras e o uso de ferramentas simples, bem como o envolvimento de toda a comunidade no Projeto de Educação Ambiental Vida do Solo como uma maneira concreta e efetiva de mudar a dura realidade dos agricultores familiares do semiárido, mantendo características intrínsecas à agricultura familiar, em uma relação particular de pertença à Terra, ao seu local de trabalho e habitação, agrupando a diversidade produtiva e associando práticas agroecológicas sustentáveis com conservação ambiental, possibilitando a produção e preservação, ao mesmo tempo.

Palavras-chave: Empreendedorismo. Sustentabilidade. Agricultura familiar.

\begin{abstract}
The present paper investigated how an environmental education project created by a family farmer, in a farmstead located in the Brazilian semi-arid region, specifically in the community of Mucambo, Riachão do Jacuípe, Bahia, is able to combine entrepreneurship techniques in rural areas, developing and using simple and innovative tools in the management and cultivation of the soil, animal husbandry, food production and water storage for human and animal consumption, to the point of becoming a national and international reference. The purpose of this paper is therefore to understand the importance of entrepreneurship, combined semi-arid. In order to achieve this goal, it was adopted a case study and other research tools like field survey, observation techniques and structured interview with a qualitative approach
\end{abstract}


${ }^{1}$ Adelson Ferreira Soares.Graduando em Administração da Universidade do estado da Bahia -UNEB, Campus XI - Serrinha-BA. E-mail:adelsonferreirasoares@ hotmail.com.

2 Janúzia Souza Mendes. Economista. Professora Adjunta da Universidade do Estado da Bahia - UNEB, Campus XI, Serrinha. E-mail:januziamendes@gmail.com.

simple tools as well as the involvement of the whole community in the Environmental Education Project Life of Soil as a concrete and effective way to change the harsh reality of the family farmers from semi-arid, maintaining characteristics that are intrinsic to family farming, in a particular relation of belonging to the land, their place of work and dwelling, grouping productive diversity and associating sustainable agroecological practices with Environmental conservation, enabling production and preservation at the same time.

Keywords: Entrepreneurship. Sustainability. Family farming.

\section{INTRODUÇÃO}

Diante da realidade de escassez de recursos naturais e financeiros que o homem do campo enfrenta na agricultura brasileira, principalmente na familiar, este trabalho buscará investigar e compreender como um projeto de educação ambiental criado em um sítio no semiárido baiano conseguiu tornar-se um exemplo de empreendedorismo rural sustentável.

Está cada vez mais evidente que o que pode e vem fazendo a diferença nesse contexto é o empreendedorismo. Embora "este" como prática diária esteja ainda aquém da realidade de muitos agricultores familiares, mesmo que tenham surgido experiências exitosas em diversos locais com realidades distintas.

O agricultor familiar tem como característica marcante uma relação particular de pertencimento com a terra e seu local de trabalho e moradia e é na diversidade produtiva também marcante desse setor que encontra motivos para produzir e gerar a renda da qual depende a sobrevivência de toda sua família, garantindo assim sua permanência no campo.

O objetivo geral deste trabalho é, portanto, compreender a importância do empreendedorismo, combinado com a educação ambiental para a mudança de vida dos agricultores familiares, diante da realidade cruel, que inclui a escassez de recursos naturais e financeiros na zona rural do semiárido baiano.

Procurará identificar em seus objetivos específicos as ideias e invenções que possibilitaram aliar práticas de sustentabilidade com a convivência no semiárido, apontar as dificuldades encontradas dentro e fora do projeto e descrever como desenvolve habilidades de cultivo e manejo do solo associado a práticas ecológicas. 
Também investigará as técnicas de empreendedorismo que são utilizadas na zona rural, para o desenvolvimento de ferramentas inovadoras, criação de animais, produção de alimentos e armazenamento de água para consumo humano e animal e para produção, associando preservação ambiental e práticas agroecológicas e sustentáveis no semiárido baiano, possibilitando produzir e preservar com respeito à natureza, educando, gerando renda e desenvolvimento, convivendo com o bioma da caatinga e a dura realidade de escassez de água existente no semiárido.

Desta forma justifica-se a realização deste estudo tendo em vista a importância que o empreendedorismo rural sustentável e suas práticas têm e vem trazendo para a agricultura familiar, possibilitando desenvolvimento local sustentável, aliado a educação ambiental de toda uma comunidade, buscando manter as pessoas no campo, gerando renda e tornando-se referência local, nacional e internacional.

Além disto, há uma escassez na literatura e de estudos sobre este tipo de empreendimento no campo, voltados para a produção e preservação do meio ambiente, aliando técnicas simples de manejo e uso do solo.

Este trabalho foi organizado contemplando, além desta introdução (1), o referencial teórico utilizado como embasamento desta pesquisa (2), os procedimentos metodológicos empregados para a realização do estudo (3), a apresentação dos resultados, intitulado como: aspectos transformadores e inovadores (4) e as considerações finais (5).

\section{REFERENCIAL TEÓRICO}

\subsection{Empreendedorismo}

Com tantas realidades sociais e frente a uma crise econômica e financeira mundial, o empreendedorismo tornou-se tema de muitas discussões no mundo acadêmico, corporativo e na sociedade em geral. Embora seja um tema bastante atual, vários autores como Schumpeter, Dolabela, Kaufmann e outros, há um bom tempo, já sinalizavam sua importância como alternativa e meio de geração de emprego, renda e desenvolvimento econômico e social. (SCHUMPETER, 1952), descreve o empreendedor como aquele que destrói a ordem econômica existente pela introdução de novos produtos e serviços, e pela criação de novos recursos materiais.

A capacidade de empreender de um indivíduo está na descoberta de suas capacidades e potencialidades, no poder de acreditar em seus sonhos e ideais, no correr o risco e na busca de concretizá-los através dos mais diversos meios que ele seja capaz de criar e/ou produzir 
de maneira a modificar todo um contexto social através de técnicas de produção inovadoras, na criação de novas tecnologias e na forma de conduzir os diversos processos organizacionais e operacionais em vários setores e segmentos da sociedade.

Segundo (DOLABELA, 2008), para o empreendedor o ser é mais importante do que o saber. A empresa é a materialização do sonho. E é através dessa materialização, concretização que ele faz acontecer às transformações desejadas. De acordo com (KAUFMANN, 1990), a capacidade empreendedora está na habilidade de inovar, de se expor a riscos de maneira inteligente, e de se ajustar as rápidas e contínuas mudanças do ambiente de forma rápida e eficiente.

O empreendedor é alguém que não tem medo de correr riscos nem de fracassar na busca pela concretização de suas ideias e objetivos, é um grande imaginário, visionário, que gosta e aceita desafios muitas vezes estimulados por ele mesmo para criar algo novo, mesmo que isso seja incerto (e quase sempre é), e que ele tenha que pagar um alto preço por correr esse risco. É incansável ou até mesmo insaciável, está sempre alçando novos voos em horizontes desfavoráveis e desconhecidos com o desejo de inovar e romper barreiras em busca da concretização de seus sonhos.

Empreendedor é uma pessoa que imagina, desenvolve e realiza visões, além de ser uma pessoa criativa, marcada pela capacidade de estabelecer e atingir objetivos, mantendo um nível de consciência do ambiente em que vive e utilizando-o para detectar oportunidades de negócios. (FILION, 1999, p. 5)

Sua capacidade imaginativa vai além do convencional ou do inexistente, ele fixa metas para si e busca alcançá-las mesmo que a duras penas, nem sempre recompensadas; porém, na concretização e realização de um projeto ou invenção, o empreendedor encontra sua realização e satisfação.

É o processo de criar algo diferente e com valor, dedicando tempo e esforços necessários, assumindo os riscos financeiros, psicológicos e sociais correspondentes e recebendo as conseqüentes recompensas da satisfação econômica e pessoal. (HISRICH, 2009, p. 29)

O empreendedorismo tem ganhado grande relevância no cenário mundial atual por fatores como capacidade imaginativa, criativa, inventiva e de gerar valor a produtos e/ou serviços já existentes, sobrepondo-se aos modelos de desenvolvimento atuais, agregando valores como a sustentabilidade. Ainda hoje, o conceito deste termo passa por um paradigma de muitas definições e várias controversas. A palavra sustentável tem origem no latim: Sustenere "sustentar, suportar ou manter", segundo o site Origem da Palavra. 
Quando se fala em sustentabilidade é impossível ignorar sua ligação com outros termos que estão intrinsecamente ligados a ele e que o complementam, dando-lhe sentido, a exemplo das palavras: "desenvolvimento" e "ecologia". A definição clássica para desenvolvimento sustentável surgiu com o Documento Nosso Futuro Comum, elaborado em 1987, pelo World Comission on Environment and Desevelopment, conhecido como Relatório Brundtland. Este documento afirma que o desenvolvimento sustentável é: a possibilidade de satisfazer as necessidades do presente, sem comprometer as possibilidades de sobrevivência das futuras gerações. (NOSSO FUTURO COMUM, 1987)

O desenvolvimento sustentável possui duas vertentes: Uma que privilegia o aspecto meramente econômico relacionado ao consumo de energia e recursos naturais, onde (SCHUMPETER, 1982), afirma que: o desenvolvimento econômico está fundamentado em três fatores principais: as inovações tecnológicas, o crédito bancário e o empresário inovador. E outra que leva em consideração os aspectos econômicos, sociais e ambientais, como o desenvolvimento sustentável, que consiste em um modelo social e econômico de organização, baseado na visão equitativa e participativa do desenvolvimento e dos recursos naturais como fundamento para a prática econômica.

Durante o Fórum Global (Rio 92) em 1992, as ONGs produziram o seguinte conceito para Agricultura Sustentável: È aquela ecologicamente correta, economicamente viável, socialmente justa, culturalmente adaptada, que se desenvolve como um processo, numa condição democrática e participativa. (FÓRUM GLOBAL, 1992)

Pode-se concluir, portanto, a partir do exposto acima, que o desenvolvimento sustentável, embora controverso e com diversas definições, está ligado às técnicas de produção ecológicas, buscando manter e sustentar as gerações futuras através de práticas sólidas e permanentes de preservação do meio ambiente, com pensamento voltado para as necessidades de cuidar como um todo da cadeia produtiva, respeitando a natureza, seus ciclos e suas mais diferentes formas de vida, inclusive a humana, onde fatores econômicos não se sobreponham aos culturais e que democraticamente viabilizem uma justa distribuição da renda, com o objetivo de melhorar a qualidade de vida da população através da geração de emprego e renda a empoderando, tornando-se assim, na maneira mais eficaz e correta de promoção do desenvolvimento, aliado a práticas de sustentabilidade que segundo (KAYSER, 2015, p.11).

"É um conceito que prega a noção de um modelo de vida e produção que garanta as necessidades das atuais gerações sem comprometer as necessidades das gerações futuras". 
A sustentabilidade é um mecanismo capaz de manter vivo todo um sistema gerador de riquezas, pensando em estilos de produção que preservem os recursos naturais, na perspectiva de que a atual e as futuras gerações possam desfrutar de um planeta preservado.

\subsubsection{Empreendedorismo Rural Sustentável}

Nos tempos de economia agroexportadora brasileira, o desenvolvimento dependia exclusivamente da agricultura, principalmente do cultivo do café. O processo de industrialização inverteu essa lógica, tornando a indústria à principal geradora de emprego e renda, o que contribuiu para o desenvolvimento econômico e social de algumas regiões, principalmente urbanas, onde esse processo se concentrou.

Com a retomada das exportações de produtos agrícolas brasileiros, os olhares se voltaram novamente para o campo, através do agronegócio que aposta na monocultura, principalmente de grãos com produção em grande escala e mecanizada, utilizando sementes transgênicas, fertilizantes artificiais, agrotóxicos que contaminam o solo e os alimentos, sendo um grande fomentador de emprego e renda, caracterizando-se como um modelo de empreendedorismo. Já a agricultura familiar é uma atividade que possui várias diferenças em relação aos outros tipos de atividades econômicas por suas características.

A agricultura familiar é aquela em que a gestão, a propriedade e a maior parte do trabalho, vêm de indivíduos que mantêm entre si laços de sangue ou de casamento. Que esta definição não seja unânime e muitas vezes tampouco operacional. É perfeitamente compreensível, já que os diferentes setores sociais e suas representações constroem categorias científicas que servirão a certas finalidades práticas: a definição de agricultura familiar, para fins de atribuição de crédito, pode não ser exatamente a mesma daquela estabelecida com finalidades de quantificação estatística num estudo acadêmico. O importante é que estes três atributos básicos (gestão, propriedade e trabalho familiar) estão presentes em todas elas. (ABRAMOVAY, 1997, p.3)

Fatores como a baixa densidade demográfica e a distância dos maiores mercados consumidores, muitas vezes impedem que os empreendedores rurais familiares alcancem economias de escala que possam lhes assegurar competitividade. É essencial para o empreendedor rural saber tirar proveito de todas as oportunidades que o meio rural possa lhe possibilitar, inclusive associando com criatividade atividades que agreguem valor a tudo que é produzido e cultivado no campo.

Afirma (VEIGA, 2002), que: as chaves para o desenvolvimento regional rural no Brasil estão ligadas a capacidade de empreendedorismo, que possibilita a geração de emprego.

O empreendedorismo rural sustentável pode desempenhar papel importante na geração de novos empregos e mais desenvolvimento, bastando para isso que os agricultores acreditem em seu potencial e atuem de maneira criativa, inovadora, utilizando ferramentas das quais 
dispõem e colocando-as a serviço de sua imaginação, agregando valor às atividades tipicamente exógenas ao meio rural, como passeios turísticos, trilhas ecológicas educativas, circuitos culturais e recreativos e de cicloturismo, que podem ser exploradas de maneira inteligente, capaz de potencializar o empreendimento rural, melhorando sua renda, além de aliar tudo isso a preservação do meio ambiente.

A agricultura familiar tem características distintas em comparação à agricultura não familiar, sendo esta última balizada pelo agronegócio que aposta na monocultura com produção em grande escala e mecanizada, utilizando sementes geneticamente modificadas, e grandes quantidades de agrotóxicos. Ao passo que na agricultura familiar a gestão da propriedade é dividida pela família e a atividade produtiva agropecuária é a principal fonte geradora de renda.

O agricultor familiar tem uma relação particular e íntima com a terra, seu local de trabalho e moradia. A diversidade produtiva é uma característica marcante desse setor, aliado ao que afirma (CELLA, 2002), o objetivo primordial do produtor rural é permanecer no campo, mesmo diante de tamanhas dificuldades enfrentadas cotidianamente.

É considerado agricultor familiar e empreendedor familiar rural aquela pessoa que pratica atividades no meio rural, possui área de até quatro módulos fiscais, mão de obra da própria família, renda familiar vinculada ao próprio estabelecimento e gerenciamento do estabelecimento ou empreendimento pela própria família. (BRASIL, 2006)

Dados do Censo Agropecuário de 2006 mostram que 84,4\% do total dos estabelecimentos agropecuários brasileiros pertencem a grupos familiares. São aproximadamente 4,4 milhões de estabelecimentos, sendo que a metade está localizada na Região Nordeste constituindo a base econômica de $90 \%$ dos municípios brasileiros com até 20 mil habitantes; responde por $35 \%$ do produto interno bruto nacional; e absorve $40 \%$ da população economicamente ativa do país. Produz $87 \%$ da mandioca, $70 \%$ do feijão, $46 \%$ do milho, $38 \%$ do café, $34 \%$ do arroz e $21 \%$ do trigo do Brasil.

Na pecuária, é responsável por $60 \%$ da produção de leite, além de $59 \%$ do rebanho suíno, $50 \%$ das aves e $30 \%$ dos bovinos do país, possuindo, portanto importância econômica relevante, atrelada ao fornecimento do mercado interno e controlando a inflação dos alimentos consumidos pelos brasileiros. Assim sendo, a agricultura familiar se constitui como uma grande força motriz capaz de gerar emprego e renda, manter o homem do campo no campo, evitando o êxodo rural e a superpopulação das grandes cidades brasileiras, evitando graves problemas sociais. 
O PRONAF, (Programa Nacional de Fortalecimento da Agricultura Familiar), que objetiva promover o desenvolvimento sustentável da agricultura familiar é o seu principal apoiador e por meio dele, agricultores familiares podem acessar várias linhas de crédito de acordo com suas necessidades e o seu projeto.

O processo de construção de uma agricultura realmente sustentável implica na substituição imediata de fertilizantes artificiais e agrotóxicos que agridem e contaminam o meio ambiente, incorporando uma nova maneira de cultivar e lidar com a terra, produzindo alimentos com insumos originários da própria natureza, respeitando o meio ambiente e todo tipo de vida nele existente.

Não se pode e nem se deve, nos dias atuais, ignorar a relevante contribuição da agricultura familiar para o crescimento do país, pois grande parte do seu desenvolvimento econômico e social, necessariamente passa por ela, devendo a mesma ser mais valorizada através de políticas públicas governamentais, que garantam seu fortalecimento, principalmente no semiárido nordestino, onde as condições financeiras e climáticas são extremamente desfavoráveis.

O clima semiárido ocorre numa grande área do território brasileiro, principalmente no Nordeste, caracterizado por chuvas em pouca quantidade e um índice pluviométrico anual em torno de 700 milímetros, o que dificulta o desenvolvimento da agricultura e pecuária, gerando sérias consequências para as pessoas que vivem nessa extensa área de terra localizada na região centro-norte da Bahia; região oeste dos estados de Sergipe, Alagoas, Pernambuco, Paraíba, Rio Grande do Norte; região centro-sul do Ceará; sul e sudeste do Piauí e parte de Minas Gerais, como o norte mineiro e o Vale do Jequitinhonha.

Mais de 23,8 milhões de brasileiros vivem na região, segundo estimativa do Instituto Brasileiro de Geografia e Estatística (IBGE, 2014), sendo aproximadamente 61,97\% na área urbana e de $38,03 \%$ no espaço rural.

Caracterizado pelo bioma da caatinga, que é único no mundo, esse clima é também chamado de tropical semiárido. É um clima tipicamente seco e quente, com pouca variação de temperatura durante o ano. A média anual fica entre $25^{\circ} \mathrm{C}$ e $28^{\circ} \mathrm{C}$. Com poucas chuvas, que se concentram entre os meses de janeiro a maio e não são distribuídas uniformemente.

As regiões semiáridas são caracterizadas, de modo geral, pela aridez do clima, pela deficiência hídrica com imprevisibilidade das precipitações pluviométricas e pela presença de solos pobres em matéria orgânica. $\mathrm{O}$ prolongado período anual eleva a temperatura local, caracterizando a aridez sazonal. (SILVA, 2006, p. 15) 
O semiárido brasileiro é um espaço com grande concentração de terra, da água e dos meios de produção e comunicação, que historicamente sempre estiveram nas mãos de uma pequena elite. Esta situação gera níveis altíssimos de exclusão social e de degradação ambiental, sendo fatores determinantes da crise socioambiental e econômica vivida na região.

A seca, principalmente no nordeste, é um dos principais problemas sociais do Brasil na atualidade, sendo responsável pelo sofrimento de milhares de famílias que habitam essa região e mesmo resistem a esta triste realidade há séculos, necessitando de políticas governamentais mais eficazes, que possam garantir o armazenamento e distribuição de água para consumo humano, animal e para a produção de alimentos durante todo o ano, o que amenizaria tamanho sofrimento dessas famílias.

\subsubsection{Educação Ambiental}

Desde o tempo colonial a educação está baseada na subordinação das pessoas, em sua maioria crianças e jovens não tem uma educação contextualizada, algo que lhes permitiria serem protagonistas de sua própria história. Por isso, ainda, a sociedade está preso a estigmas de não valorização do nosso bioma caatinga e temos o desafio de enfrentar o modelo dominante de desenvolvimento, que propaga o semiárido como lugar de morte e não de vida. A educação do campo ainda está pautada num modelo urbano, embora através da Lei de Diretrizes e Bases da Educação Nacional, (BRASIL, 1996), é reconhecida a diversidade do campo, bem como há orientações aos sistemas de ensino de como promover a oferta dessa educação, atendendo a sua realidade.

Uma pessoa aprende ao dar significado a um conteúdo ou a uma experiência que tenha sido refletida, embora cada pessoa faça esse movimento de sua própria maneira, vinculando questões inerentes a sua realidade, tendo como base a sua temporalidade e os saberes próprios. Quando se trata de educação ambiental, pensa-se logo na palavra ecologia que tem origem no grego "oikos" que significa casa, e "logos", estudo. Ecologia é, portanto a ciência que estuda o meio ambiente e o seres vivos que vivem nele.

Como ciência, a ecologia iniciou-se de uma forma isolada, desconectada. Nos anos 1960, surgem as lutas ecológicas no mundo e as pessoas faziam movidas por causas como: "Não deixem derrubar aquela árvore", "Não deixem construir tal empreendimento, pois irá destruir a natureza, contaminar os rios", etc. A luta ambientalista no Brasil e no mundo tem sido travada desde os anos 1960 segundo (MILANEZ, 2011). 
Educação ambiental são processos por meio dos quais o indivíduo e a coletividade constroem valores sociais, conhecimentos, habilidades, atitudes e competências voltadas para a conservação do meio ambiente, bem de uso comum do povo, essencial à sadia qualidade de vida e sua sustentabilidade. (BRASIL, 1999)

Esse conceito define a Política Nacional de Educação Ambiental. Essa política deve ser um componente efetivo e imutável da educação nacional, devendo está contextualizada, de maneira articulada, em todos os planos e modalidades do processo educativo, em caráter formal e informal. Especificamente tratando-se de educação ambiental, ainda há muitos desafios, porém, avançou-se bastante desde os tempos de seu surgimento.

Quando o aprendizado se torna prática cotidiana e é colocado a favor da sociedade, todos saem ganhando, a exemplo de vários casos exitosos mundo a fora de educação contextualizada e transformadora. Portanto, há uma necessidade de se criar, incentivar e apoiar nas comunidades e escolas projetos de educação ambiental permanentes voltados para crianças e adolescentes, sobretudo aqueles residentes na zona rural, com o intuito de valorizar as suas origens, criar nelas sentimento de pertencimento, mostrando a necessidade de preservar o meio ambiente, tudo isso vivenciado na prática do dia a dia.

\section{METODOLOGIA}

Tendo utilizado estudo de caso que segundo (YIN, 2005, p. 19), "é apenas uma das muitas maneiras de se fazer pesquisa em ciências sociais". Esses estudos são feitos com a finalidade de detalhar uma situação específica, para poder compreendê-la melhor e de maneira mais eficaz.

O estudo de caso é uma investigação empírica que "investiga um fenômeno contemporâneo em profundidade e em seu contexto de vida real, especificamente quando os limites entre o fenômeno e o contexto não são claramente evidentes". (YIN, 2010, p. 39)

Foi, empregada também, pesquisa exploratória com abordagem qualitativa que:

Trabalham com o universo de significados, motivos, aspirações, crenças, valores e atitudes, o que corresponde a um aspecto mais profundo das relações, dos processos e dos fenômenos que não podem ser reduzidos a operacionalização de variáveis. (MINAYO, 2010, p. 21)

Como técnica de coleta a observação, utilizou-se entrevistas e análise documental. A observação conforme (SEVERINO, 2007, p. 123), "é um procedimento que permite acesso aos fenômenos estudados", é, porém uma etapa essencial para qualquer modalidade de pesquisa, pois através dela o pesquisador pode notar e ressaltar características importantes e fundamentais em sua pesquisa, a exemplo desta que foi realizada no Projeto de Educação Ambiental Vida do Solo na Comunidade de Mucambo, no Município de Riachão do Jacuípe, Bahia, utilizando como alvo de pesquisa o idealizador do projeto Abelmanto Carneiro, 
agricultores familiares e estudantes da comunidade por participarem e vivenciarem ativamente o projeto.

Através da coleta de dados e utilizando a entrevista pessoal e a estruturada que para (SEVERINO, 2007, p. 125), "são aquelas em que as questões são direcionadas e previamente estabelecidas, com determinada articulação interna", contudo, são capazes de nortear o entendimento do pesquisador sobre o assunto a ser pesquisado, por meio de amostra não probabilística autogerada.

Também fora utilizada a análise documental que segundo (CELLARD, 2008, p. 295), “favorece a observação do processo de maturação ou de evolução de indivíduos, grupos, conceitos, conhecimentos, comportamentos, mentalidades, práticas, entre outros”. E por fim como técnica de análise de dados, foi utilizada a análise de conteúdo que segundo (GODOY, 1995), é um método que possibilita ao pesquisador compreender as características, estruturas e modelos que estão compondo o conteúdo a ser estudado, permitindo assim uma compreensão ampla da pesquisa que ora está sendo apresentada.

\section{Aspectos Transformadores e Inovadores}

"Acreditar naquilo que agente faz e gosta de fazer e faz por amor é o primeiro passo para a realização", diz Abel. A iniciativa e paixão, a utilização criativa dos poucos recursos disponíveis aliados a possibilidade de fracassar, além de aceitar correr riscos, assumindo desafios faz de Abel um visionário, como afirma (SCHUMPETER, 1952), um destruidor da ordem; alguém que busca sair do convencional, e introduz em seu sítio com suas "invencionices", uma maneira inovadora de lidar e de se relacionar com a natureza, fazendo dele um grande empreendedor, capaz de aliar, na zona rural, sustentabilidade e desenvolvimento.

O desenvolvimento é produzido quando a capacidade criativa do ser humano converge para a descoberta das suas potencialidades, assim o homem passa a agregar valor ao seu ambiente, modificando-o e enriquecendoo.(FURTADO, 2007, p. 05)

Foi o que fez Abel, em seu sítio: Tornou-o um empreendimento rural sustentável e experimental aberto a visitação, (BARRETO, 1998, p. 190), "define empreendedorismo como a habilidade de se conceber e estabelecer algo partindo de muito pouco ou quase nada". 
Com a introdução de tecnologias como a construção de vários tipos de cisternas, barragem subterrânea, barragenzinhas sucessivas, barreiro trincheira, todos voltados para a captação de águas da chuva, que serão utilizadas em todo período do ano para consumo humano, dessedentação animal e irrigação da plantação, principalmente nos períodos de estiagem, garantindo uma segurança hídrica para sua propriedade, que conta hoje com um potencial de armazenamento de aproximadamente 5,3 milhões de litros de água, enquanto sua carga de consumo é de aproximadamente 1,7 milhão de litros de água por ano, o que lhe traz bastante segurança para enfrentar os períodos de estiagem.

Plantio de palma adensada em curva de nível que evita a erosão do solo, não permitindo a degradação e preservando o mesmo, além de garantir alimentação para o seu rebanho durante todo o ano; capríl, onde os animais são confinados e se alimentam em cochos construídos por Abel, estocagem de alimentos para caprinos, ovinos e bovinos por meio da técnica de silagem; bebedouro inteligente para os animais, onde, através de um sistema de nível, a água chega até o mesmo, mantendo-lhe sempre cheio, mesmo com os animais consumindo a água; estufa com viveiro de mudas de plantas frutíferas e árvores da caatinga, garantindo o que podemos chamar de recaatigamento (plantio de árvores nativas da caatinga), enriquecendo-a com o plantio de capim, permitindo recuperar determinadas áreas degradadas em seu sítio; cerca elétrica para impedir a evasão dos animais; irrigação alternativa através da bomba malhação giratória (assim denominada por Abel), kit de irrigação com micro aspersores feitos de materiais reciclados como tubos de caneta e hastes de pirulito, sendo bastante utilizados no sítio.

A fabricação e comercialização dos mesmos possibilitam geração de renda para os envolvidos no projeto; biodigestor para produção de gás metano a partir das fezes dos animais, permitindo um menor uso do fogão a lenha e, por conseguinte, da madeira da caatinga como também economia na compra de botijão a gás; fossa séptica que trata a água dos banheiros permitindo a devolução da mesma à natureza e sua reutilização para molhar a plantação; apiário com 22 caixas de colméias de abelhas italianas, onde são produzidos mel e própolis com base ecológica e que serão vendidos, buscando gerar renda e preservar a espécie, pois Abel faz remoção de colméias que se instalam em locais inadequados garantindo a sobrevivência da espécie.

Com essas experiências aplicadas e aliando práticas agroecológicas e sustentáveis, Abel vive hoje tranqüilo e seguro no campo, ao passo em que está buscando desenvolver outras novas 
tecnologias. Como afirma (PAVITT, 2002), o processo de inovação é a transformação do conhecimento em inovação, a exemplo das tecnologias sociais que surgem da gestão e difusão do saber popular nas comunidades. O projeto conta ainda com um espaço para estudo, cultura e lazer onde são feitas palestras, cursos de formação e troca de experiências, uma cozinha comunitária para a produção de bolos, doces, biscoitos, polpas de frutas principalmente nativas como o umbu, (vale destacar um estudo feito com toda comunidade para mapear os pés da fruta nativa da caatinga no entorno de mil e quinhentos metros do sítio) com o intuito de preservar a mesma e facilitar a colheita, confecção de artesanatos, alojamento para visitantes, tudo isso construído com recursos das vendas de suas “invencionices”, principalmente a bomba malhação.

Todas essas exitosas experiências aplicadas e a capacidade inovadora e empreendedora de Abel tem tornado o Projeto Ambiental Vida do Solo em uma referência local, nacional e até internacional de empreendedorismo rural sustentável no semiárido baiano, capaz de gerar renda e proteger ao mesmo tempo o meio ambiente .

\subsection{O Município de Riachão do Jacuípe e a Comunidade de Mucambo}

Pela lei Provincial n ${ }^{\circ} 276$ de 23 de maio de 1847 o arraial de Riachão do Jacuípe foi elevado à categoria de Freguesia pertencendo a Jacobina. Em $1^{\circ}$ de agosto de 1878 , é criado política e administrativamente o Município de Riachão do Jacuípe na categoria de Vila Imperial e foi instalada em 25 de outubro do mesmo ano. Em 14 de agosto de 1928, de acordo com (SOARES, 2010), a Vila foi elevada a categoria de cidade com a instalação da Câmara municipal de vereadores, hoje situada a Praça Joaquim Carneiro da Silva no centro de Riachão do Jacuípe, Estado da Bahia.

O município está situado na mesorregião nordeste da Bahia, microrregião de Serrinha, possui uma área territorial de $1.227 \mathrm{Km}^{2}$, a distância da capital baiana é de $183 \mathrm{~km}$, possui altitude de 240 metros acima do nível do mar e está situada no semiárido baiano. A sua média anual de temperatura é de $24.6^{\circ} \mathrm{C}$; a máxima $32.2^{\circ} \mathrm{C}$; mínima de $20.9^{\circ} \mathrm{C}$. A pluviosidade média é de $557 \mathrm{~mm}$, a máxima de $1.166 \mathrm{~mm}$ e a mínima de $84 \mathrm{~mm}$ até então registrados. O município está Inserido no polígono da seca com incidência bastante alta. Possui uma população estimada no ano de 2016 em 34.715 habitantes distribuídos entre a sede do Município, um distrito, duas vilas, treze povoados, comunidades e fazendas. 
Ao nordeste do Município de Riachão do Jacuípe, e distante $18 \mathrm{~km}$, encontram-se a comunidade de Mucambo na região do Povoado de Chapada, onde na Fazenda Pau de Colher, contando com apenas dez hectares um pequeno sítio vem se destacando por causa de um projeto de educação ambiental intitulado "Projeto Vida do Solo" idealizado e executado pelo agricultor familiar Abelmanto Carneiro.

“O Projeto Vida do Solo é um trabalho voluntário de educação ambiental com crianças e adolescentes, junto com as famílias e a escola local, desenvolvendo aulas práticas e de campo com base na agroecologia e técnicas de convivência com o semiárido, tem como objetivo, sensibilizar as pessoas a cuidarem do ambiente, principalmente a vida no espaço em que vive, fazendo com que o homem e a natureza vivam em harmonia um cuidando do outro a viver", conclui Abelmanto Carneiro, conhecido como Abel, idealizador do Projeto Vida do Solo.

Para (DRUCKER, 1986), o empreendedorismo pode ser um importante ponto na história das relações entre o indivíduo e a comunidade. Enfatiza Abel que no início não foi fácil. "Fui muito chamado de doido, louco de preguiçoso..." e ainda hoje continua não sendo diante das dificuldades encontradas para conscientizar parte da comunidade, agricultores familiares e a população em geral da necessidade de produzir sem destruir a natureza. Foi a partir daí que surgiu a ideia de se criar um projeto começando pelas crianças e adolescentes da escola local, onde as mesmas, através de aulas de campo pudessem conhecer mais profundamente a natureza.

Ao aplicar técnicas simples de manejo e conservação do solo com o pensamento voltado para a preservação do meio ambiente, as crianças e adolescentes que participam do Projeto Vida do Solo aprendem desde cedo a valorizar o contexto em que vivem e também a preservar e cuidar do meio ambiente.

Hoje, toda a comunidade se engaja na causa ambiental, tornando-se uma grande aliada da natureza, aonde vem sendo desenvolvidas varias tecnologias de convivência com o semiárido, possibilitando gerar renda, manter as famílias no campo com dignidade e educar a população para a grande necessidade de preservar o meio ambiente.

\section{Considerações Finais}

Tendo em vista os argumentos apresentados, pode-se contudo, concluir que o empreendedorismo tornou-se uma importante ferramenta para o desenvolvimento econômico e social, capaz de proporcionar grande melhoria na qualidade de vida e na geração de renda 
dos agricultores familiares, especialmente aqueles do semiárido, que buscam implantar em suas propriedades rurais inovações capazes de agregar valor ao que é produzido.

Considera-se, sem dúvidas, que e as entrevistas e as visitas de campo foram os grandes facilitadores durante todo o transcurso desse trabalho, pois mostraram de maneira prática e clara todo o funcionamento, organização e finalidade do Projeto Vida do Solo, que ao longo dos anos vêem conscientizando toda uma comunidade da necessidade de se incorporar a preservação ambiental com produção sustentável.

Também, as visitas ao sítio foram muito proveitosas, pois mostraram na prática como as técnicas inovadoras implantadas através do projeto e sua capacidade empreendedora possibilitaram mudar a realidade de vida de muitas famílias do semiárido por meio de ações simples, porém eficazes.

Através das técnicas implantadas no sítio, Abel, como é conhecido, associa produção e sustentabilidade em uma pequena propriedade rural no semiárido baiano, mesmo diante de tantas dificuldades encontradas. Para atingir seus objetivos criou o projeto de educação ambiental capaz de envolver a escola e a comunidade em torno do mesmo desejo: produzir e preservar.

As atitudes inovadoras e criativas, bem como o espírito aventureiro e seu jeito de se relacionar com a natureza fazem de Abel, um empreendedor, que vê através da preservação ambiental, um modelo capaz de gerar renda e desenvolvimento econômico na agricultura familiar do semiárido baiano, provocando uma clara mudança de atitude na maneira de conviver com essa realidade de escassez.

O empreendedorismo rural sustentável hoje desempenha um papel importantíssimo na geração de renda e desenvolvimento: quando os agricultores acreditam em seu potencial e atuam de maneira criativa e inovadora, buscando agregar valor as atividades desempenhadas em suas propriedades.

Essas novas atitudes conseguem aliar desenvolvimento rural com sustentabilidade, mesmo diante das dificuldades encontradas no sertão baiano, principalmente a baixa pluviosidade, que impede o desenvolvimento da agricultura e da pecuária trazendo sérias implicações para todos que vivem no semiárido.

Buscando conviver com essa realidade, são utilizados vários mecanismos, a exemplo do armazenamento de água por meio das diversas tecnologias, que são capazes de garantir uma segurança hídrica amenizando essa dura realidade. Como sugestões para trabalhos futuros 
vêm à necessidade de se estudar os impactos sociais e econômicos na comunidade de Mucambo após esses anos de existência do Projeto Vida do Solo.

\section{REFERÊNCIAS}

ABRAMOVAY, Ricardo. Paradigmas do Capitalismo Agrário em questão. São Paulo. Anpocs, Unicamp, Hucitec, 1992. "Uma nova extensão para a agricultura familiar". In: Seminário Nacional De Assistência Técnica e Extensão Rural. Brasília, DF, Anais, 1997, p. 29 (Texto para discussão).

BARRETO, L. P. Educação para o Empreendedorismo. Salvador: Escola de Administração de Empresas da Universidade Católica de Salvador, 1998.

BIBLIOTECA.ibge.gov.br/visualização/periódicos/51/agro_2006.pdf,acesso em 25 de abril de 2017.

BRASIL, Ministério de Educação e Cultura. LDB - Lei no 9394/1996, de 20 de dezembro de 1996. Estabelece as diretrizes e bases da Educação Nacional. Brasília : MEC, 1996.

BRASIL, Ministério da Educação e do Desporto, Lei n. 9.795/1999, de 27 de abril de 1999. Dispõe sobre a educação ambiental, institui a Política Nacional de Educação Ambiental e dá outras providências. Brasília, MEC, 1999.

BRASIL, Política Nacional da Agricultura Familiar e Empreendimentos Familiares Rurais. Lei $\mathbf{n}^{\circ} \mathbf{1 1 . 3 2 6 / 2 0 0 6}$, de 24 de julho de 2006.

CELLA, D. Revista de Administração, São Paulo v.37, n.4, p.49-57, outubro/dezembro 2002.

CELLARD, A. A análise documental. In: POUPART, J. et al. A pesquisa qualitativa: enfoques epistemológicos e metodológicos. Petrópolis, Vozes, 2008.

DOLABELA, F. Oficina do empreendedor. São Paulo: Editora de Cultura, 2008.

DRUCKER, Peter F. Inovação e Espírito Empreendedor - Entrepreneurship. $6^{\mathrm{a}}$ ed. São Paulo: Pioneira, 1986.

FILION, L. J. Empreendedorismo: empreendedores e proprietários gerentes de pequenos negócios. Revista de Administração de empresas da USP. São Paulo, v. 34, n. 2, p. 05-28, abril/jun. 1999.

FÓRUM GLOBAL, Tratado das ONGs relativo à agricultura sustentável. Rio de Janeiro, 1992. Mimeografado.

FURTADO, Celso. Formação econômica do Brasil. 34 ed. São Paulo: Companhia das Letras, 2007.

GODOY, Arilda Schimidt. Introdução à pesquisa qualitativa e suas possibilidades. RAERevista de Administração de Empresas, São Paulo, v. 35, n.2, p.57-63, 1995. 
HISRICH, Robert. D. PETERS, Michael, P. SHEPHERD, Dean A. Empreendedorismo. $7^{\mathrm{a}}$ ed. Porto Alegre: Bookman, 2009.

KAUFMANN, L. Passaporte para o ano 2000: como desenvolver e explorar a capacidade empreendedora para crescer com sucesso até o ano 2000. São Paulo: Makron Books, 1990.

KAYSER, Arno, Ecologia em dias tão confusos, $1^{\text {a }}$ ed. Edipucrs, 2015.

MDA. Google Analytics. Disponível em:

http://www.mda.gov.br/sitemda/noticias/o-que-é-agricultura-familiar, acesso em 15 de abril de 2017.

MILANEZ, Francisco, Ecoalfabetização, manual de sobrevivência em um planeta em extinção, $1^{\text {a }}$ ed. Edipucrs, 2011.

MINAYO, Cecília de Souza (org.). Pesquisa Social: teoria, método e criatividade. $29^{\mathrm{a}}$ ed. Petrópolis, RJ: Vozes, 2010.

NOSSO FUTURO COMUM, Documento elaborado em 1987, pelo World Comission on Environment and Desevelopment, conhecido como Relatório Brundtland.

PAVITT, Keith. Changing Patterns of Usefulness of University Research: Opportunities and Dangers Sectoral. Disponível em htt://www.merit.unu.edu/publications/papers/200210 pavit.pdf. Acesso em 26 de abril de 2017.

SCHUMPETER, Joseph. Can capitalism survive? (New York: Harper \& Row, 1952), p.72.

SCHUMPETER, Joseph. Teoria do desenvolvimento econômico: uma investigação sobre lucros, capital, crédito, juros e o ciclo econômico. São Paulo: Abril Cultural, 1982.

SEVERINO, A. Joaquim. Metodologia do Trabalho Científico. 23 ed. Cortez, 2007.

SILVA, Roberto Marinho Alves. Entre o Combate à Seca e a Convivência com o Semiárido: Transições paradigmáticas e sustentabilidade do desenvolvimento. Tese de Doutorado. Centro de Desenvolvimento Sustentável. Universidade de Brasília. Brasília-DF, 2006. 135 p.

SOARES, Amarílio. Histórias de Riachão do Jacuípe. 1ª ed. Riachão do Jacuipe, 2010.

SOUZA, M. RABELO E TEIXEIRA, D.E. Compostos à Base de Madeira. Apostila do curso de Capacitação de Agentes Multiplicadores em Valorização da Madeira e dos Resíduos Vegetais, MMA/IBAMA, 2002.

VEIGA, J.E. Cidades Imaginárias: o Brasil é menos urbano do que se calcula. CampinasSP: Editora Autores Associados, 2002, Estudos Sociedade e Agricultura.

YIN, R. K. Estudo de caso: Planejamento e métodos. 3. ed. Porto Alegre: Bookman, 2005.

YIN, R.K. Estudo de caso: planejamento e métodos. 4. ed. Porto Alegre: Bookman. 2010. 
